\title{
Electronic Structure of Ytterbium(III) Solvates - A Combined Spectroscopic and Theoretical Study
}

\author{
Nicolaj Kofod, ${ }^{\dagger}$ Patrick Nawrocki, ${ }^{\dagger}$ Carlos Platas-Iglesias, ${ }^{*}, \ddagger$ Thomas Just Sørensen ${ }^{*}$, \\ † Department of Chemistry and Nano-Science Center, University of Copenhagen, Universitetsparken 5, 2100 Kø- \\ benhavn $\varnothing$, Denmark. \\ ‡ Centro de Investigacións Científicas Avanzadas and Departamento de Química, Universidade da Coruña, Cam- \\ pus da Zapateira-Rúa da Fraga 10, 15008 A Coruña, Spain
}

\begin{abstract}
The wide range of optical and magnetic properties of the lanthanide(III) ions is associated to their intricate electronic structures, which in contrast to lighter elements is characterized by strong relativistic effects and spin-orbit coupling. Nevertheless, computational methods are now capable of describing the ladder of electronic energy levels of the simpler trivalent lanthanide ions, as well as the lowest energy term of most of the series. The electronic energy levels result from electron configurations that are first split by spin-orbit coupling into groups of energy levels denoted by the corresponding Russel-Saunders terms. Each of these groups are then split by the ligand field into the actual electronic energy levels known as microstates or sometimes $m_{J}$ levels. The ligand field splitting directly informs on coordination geometry, and is a valuable tool for determining structure and thus correlating the structure and properties of metal complexes in solution. The issue with lanthanide complexes is that the determination of complex structures from ligand field splitting remains a very challenging task. In this manuscript, the optical spectra - absorption, luminescence excitation and luminescence emission - of ytterbium(III) solvates were recorded in water, methanol, dimethyl sulfoxide and $N, N$ dimethylformamide. The electronic energy levels, that is the microstates, were resolved experimentally. Subsequently, density functional theory (DFT) calculations were used to model the structures of the solvates and ab initio relativistic complete active space self-consistent field (CASSCF) calculations were employed to obtain the microstates of the possible structures of each solvate. By comparing experimental and theoretical data, it was possible to determine both the coordination number and solution structure of each solvate. In water, methanol and $N, N$-dimethylformamide the solvates were found to be eight-coordinated and to have a square anti-prismatic coordination geometry. In DMSO the speciation was found to be more complicated. The robust methodology developed for comparing experimental spectra and computational results allows the solution structures of lanthanide complexes to be determined, paving the way for the design of complexes with predetermined properties.
\end{abstract}

\section{INTRODUCTION}

The lanthanides, displaced to the bottom of most charts showing the periodic table, have immense technological importance. ${ }^{1,2}$ They have found use in fields as diverse as high-performance magnets, ${ }^{3-5}$ bio-assays and bio-imaging, ${ }^{6-8} \mathrm{MRI}$ contrast agents, ${ }^{9,10}$ as well as potential use as singe-molecule magnets, ${ }^{11-14}$ and in anti-counterfeiting technologies ${ }^{15}$. This technological demand has resulted in lanthanides being declared a critical resource by the US Department of Energy. ${ }^{16}$ To solve this issue, Urban Mining has been proposed as a method to close the loop of lanthanide processing. ${ }^{17-20}$ However, further development of these techniques is hampered by a lack of understanding of the basic chemical properties of lanthanide ions in solution.

The lack of covalency in the coordination bonds to lanthanide ions makes the structures in solution exceedingly difficult to predict. ${ }^{21}$ Further, fast ligand exchange kinetics complicates the study of lanthanide(III) solution chemistry. ${ }^{9,22-28}$ In solid state, the static environment enables an understanding of structure-property relationships, ${ }^{29}$ but the increased degree of freedom in solution often results in an averaging of the observed properties, which makes structure determination difficult, ${ }^{26,30,31}$ and complicates attempts of linking a specific property to a specific structure. ${ }^{27,32}$

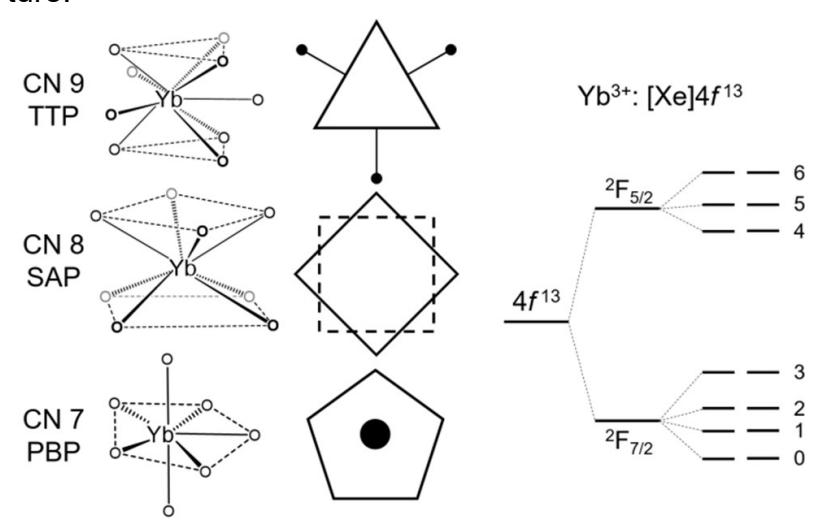

Figure 1. Left: Proposed structures of $\mathrm{Yb}^{3+}$ solvates for different coordination numbers seen from the side and from the top. Right: Schematic of the electronic structure of $\mathrm{Yb}^{3+}$. The energy levels labelled 0-6 all consist of a Kramers Doublet.

An example of this is the ongoing debate regarding the coordination number $(\mathrm{CN})$ of trivalent lanthanide ions in 
aqueous solution. ${ }^{23,33}$ The ionic radii of the lanthanides decreases across the series, ${ }^{34,35}$ an effect that is known as the lanthanide contraction. ${ }^{36,37}$ It has been proposed that this contraction leads to a change in coordination number going from 9 to 8 with the change occurring around $\mathrm{Gd}$ - referred to as the Gadolinium Break. ${ }^{23}$

Early work revealed a non-smooth variation of several properties across the series (i. e. molar volumes, heat capacities and relative viscosities) that suggested a structural change occurring across the series. ${ }^{38-40}$ Subsequent neutron diffraction, ${ }^{41} \mathrm{EXAFS}^{42}$ and ${ }^{17} \mathrm{O} \mathrm{NMR}^{43}$ data in solution supported a change in the number of coordinated water molecules from 9 to 8 around the center of the lanthanide series. Later EXAFS studies however provided results in contradiction with the early work, proposing that the aqua-ions are nona-coordinated throughout the series. ${ }^{33}$ The more recent results based on EXAFS, ${ }^{44}$ Raman spectroscopy, ${ }^{45,46}$ optical spectroscopy ${ }^{47}$ and theoretical studies ${ }^{48,49}$ support that the light lanthanide(III) aqua ions are nine-coordinated, while the heaviest lanthanide(III) ions are octa-coordinated in aqueous solutions. In this study, we aim to use high-resolution optical spectroscopy and state-of-the-art computational chemistry to determine the coordination number and structure of four $\mathrm{Yb}^{3+}$ solvates in order to - hopefully - close this discussion.

The lack of directional bonding in lanthanide coordination chemistry means that the metal-ligand interactions can be accurately described as point charges on the surface of a sphere. As a mathematical problem, this is known as the Thomson Problem. ${ }^{50}$ Identical mono-dentate ligands usually form complexes with structures that resemble the ideal polyhedra from the solution to the Thomson Problem..$^{51-53}$ The electronic energy levels of lanthanides as free ions can accurately be described using the RusselSaunders formulation which takes the spin-orbit coupling into account. ${ }^{54}$ These Russel-Saunders states contains envelopes of electronic energy levels, which we refer to as microstrates. The symmetry of the ligand field is what dictates the splitting of the Russel-Saunders term into these microstates, also denoted as $\mathrm{m}_{J}$ levels, ligand field

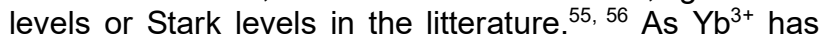
half-integer $J$ terms, the levels split into sets of degenerate Kramers Doublets. This is illustrated in Figure 1. The ${ }^{2} \mathrm{~F}_{7 / 2}$ and ${ }^{2} \mathrm{~F}_{5 / 2}$ levels split into 4 and 3 sets of microstates respectively. While it is possible for two sets to feature degenerate energy levels, this requires ligand fields with a cubic symmetry. ${ }^{57}$ Such high symmetry ligand fields are essentially impossible to achieve with the expected coordination numbers of 7 to 9 , and as such they are not relevant for this discussion. The solution for the Thomson Problem for coordination numbers 7,8 and 9 are the pentagonal bipyramid (PBP), the square antiprism (SAP) and the tricapped trigonal prism (TTP), shown in Figure 1.52, 53, $58-60$

Advances in instrumentation has led to a resolution in optical spectra that allows for the detection of individual ligand field levels. ${ }^{27,61-63}$ The ligand field splitting relates directly to the structure of the complex. However, while the energy levels can be determined, experimental data alone cannot correlate the observed transitions to a specific structure. The electronic structure of lanthanides is highly complex and presents a great computational challenge. Recently, new quantum chemical methods allowed for the electronic structure of the ground state to be calculated. ${ }^{12}$, 63-68 The electronic structure of $\mathrm{Yb}^{3+}$ consists of only two Russel-Saunders terms and is thus among the simplest of the lanthanides to treat theoretically. This allows for accurate determination of the ligand field splitting in not only the ground state, but the excited state as well.

Here, we combine optical spectroscopy and quantum chemical calculations to determine the solution structure and electronic structure of four $\mathrm{Yb}^{3+}$ solvates. The experimental and theoretical data were obtained separately. The result is that we are able to predict the solution structure of $\mathrm{Yb}^{3+}$ solvates in dimethylsulfoxide (DMSO), N,Ndimethylformaide (DMF), methanol, and water from their experimentally determined ligand field splitting. We are able to determine the coordination geometry and thus structure of the $\mathrm{Yb}^{3+}$ solvates, and the data clearly show that the coordination number of $\mathrm{Yb}^{3+}$ in water is 8 .

\section{EXPERIMENTAL AND COMPUTATIONAL SECTION}

Sample Preparation. $\mathrm{Yb}\left(\mathrm{CF}_{3} \mathrm{SO}_{3}\right)_{3}$ (Sigma Aldrich) was dissolved in DMSO-d $\left(\right.$ Eurisotop), $\mathrm{MeOH}-d_{4}$ (Eurisotop), $\mathrm{D}_{2} \mathrm{O}$ (Cambridge Isotope Laboratories, Inc.) and DMF (ChemSolute). All chemicals and solvents were used as received. All solutions were $0.1 \pm 0.0003 \mathrm{M}$. We detected no signals from other lanthanides in any spectra. No changes in absorption were observed over time.

Optical Spectroscopy. Absorption measurements were carried out on a Lambda 1050 double-beam spectrophotometer from PerkinElmer using a halogen lamp as excitation source. Air was used as a reference. Absorption was measured on an absolute scale using pure solvent and a blocked beam. Slits were kept at $1 \mathrm{~nm}$.

Steady State emission spectra at 300 and $77 \mathrm{~K}$ as well as excitation spectra at 77K were recorded on a PTI QuantaMaster8075 from Horiba Scientific using a xenon arc lamp for excitation. A constant flow of nitrogen was sent through the sample chamber to avoid condensation. All room temperature samples were measured in $10 \mathrm{~mm}$ quartz cuvettes from Starna Scientific. Cooled samples were measured in $4.2 \mathrm{~mm}$ quartz NMR tubes from Norell placed in a quartz Dewar from Horiba Scientific filled with liquid nitrogen. For emission spectra at $77 \mathrm{~K}$ excitation/emission slits were kept at $8 / 6,8 / 4,8 / 2.5$ and $8 / 5 \mathrm{~nm}$ for measurements in $\mathrm{D}_{2} \mathrm{O}$, DMF, DMSO- $d_{6}$ and $\mathrm{MeOH}-d_{4}$ respectively. For emission spectra at $300 \mathrm{~K}$ the excitation/emission slits were kept at 8/10, 8/6, 8/5 and 8/10 nm for measurements in $\mathrm{D}_{2} \mathrm{O}, \mathrm{DMF}$, DMSO- $d_{6}$ and $\mathrm{MeOH}-d_{4}$ respectively. For excitation spectra at $77 \mathrm{~K}$ the emission/excitation slits were kept at 3/16, 4/16, 2.5/16 and $4 / 16 \mathrm{~nm}$ for measurements in $\mathrm{D}_{2} \mathrm{O}$, DMF, DMSO- $d_{6}$ and $\mathrm{MeOH}-d_{4}$ respectively. Lamp fluctuations and wavelength dependent detector sensibility were corrected by using factory provided correction files.

Computational details. Geometry optimizations of $\left[\mathrm{Yb}\left(\mathrm{H}_{2} \mathrm{O}\right)_{q}\right]^{3+} \quad(q=\quad 8, \quad 9), \quad\left[\mathrm{Yb}\left(\mathrm{H}_{2} \mathrm{O}\right)_{9}\right]^{3+} \cdot 18 \mathrm{H}_{2} \mathrm{O}$, $\left[\mathrm{Yb}(\mathrm{MeOH})_{8}\right]^{3+},\left[\mathrm{Yb}(\mathrm{DMF})_{8}\right]^{3+}$ and $\left[\mathrm{Yb}(\mathrm{DMSO})_{\mathrm{q}}\right]^{3+}(q=8$, 
7) were performed using density functional theory (DFT), within the hybrid-meta-GGA approximation, with the TPSSh $^{69}$ and/or M06-2X ${ }^{70}$ exchange-correlation functionals. These functionals were found to provide accurate bond distances of the metal coordination environment in lanthanide complexes, particularly with ligands containing $\mathrm{O}$ donor atoms. ${ }^{71}$ The input structures of $\left[\mathrm{Yb}\left(\mathrm{H}_{2} \mathrm{O}\right)_{q}\right]^{3+}(q=$ $8,9)$ were taken from a previous computational study ${ }^{72}$, and modified to generate input structures for $\left[\mathrm{Yb}(\mathrm{MeOH})_{8}\right]^{3+}$. The starting geometries of $\left[\mathrm{Yb}(\mathrm{DMF})_{8}\right]^{3+}$ and $\left[\mathrm{Yb}(\mathrm{DMSO})_{\mathrm{q}}\right]^{3+}(q=8,7)$ were obtained from X-ray diffraction data. ${ }^{73}$ DFT calculations employed the largecore effective core potential for $\mathrm{Yb}\left([\mathrm{Kr}] 4 \mathrm{~d}^{10} 4 \mathrm{f}^{13}\right.$ core) and the associated [5s4p3d]-GTO valence basis set. ${ }^{74}$ All other atoms were described with the standard 6-31G(d,p) basis set. In the case of the $\left[\mathrm{Yb}\left(\mathrm{H}_{2} \mathrm{O}\right)_{9}\right]^{3+} \cdot 18 \mathrm{H}_{2} \mathrm{O}$ system, solvent effects were considered with a polarized continuum model (integral equation formalism variant). ${ }^{75}$ Frequency calculations were used to confirm that the optimized geometries correspond to local energy minima on the corresponding potential energy surface. Geometry optimizations and frequency calculations were performed with the Gaussian 09 program package. ${ }^{76}$

Complete active space self-consistent field (CASSCF) ${ }^{77}$ calculations were performed using the ORCA 4 program package (version 4.2) ${ }^{78,79}$ The active space included 13 electrons distributed in the seven $4 \mathrm{f}$-based orbitals [CAS $(13,7)]$. The starting orbitals for $\operatorname{CAS}(13,7)$ calculations were obtained from ROKS calculations performed within the local density approximation with Slater exchange $(\alpha=2 / 3)$ and WWN5 correlation. ${ }^{80,} 81$ Relativistic effects were considered with the with the all-electron second-order Douglas-Kroll-Hess (DKH2) method. ${ }^{82,}{ }^{83}$ The SARC2-DKH-QZVP basis set was used for $\mathrm{Yb},{ }^{84}$ while $\mathrm{C}$, $\mathrm{H}, \mathrm{N}, \mathrm{O}$ and $\mathrm{S}$ were described with the DKH-def2-TZVP basis set. The latter uses the exponents of the def2-TZVP basis set of Weigend ${ }^{85}$ and was re-contracted for relativistic calculations. ${ }^{86}$ CASSCF calculations were accelerated using the resolution of identity (RI-JK) approximation, ${ }^{87}$ using the SARC2-DKH-QZVP/JK auxiliary basis set for $\mathrm{Yb}$ and the Autoaux procedure to generate auxiliary basis sets for all other atoms. ${ }^{88}$ Test calculations performed using the faster ${ }^{89}$ chain of spheres RIJCOSX approximation revealed a larger splitting of the CAS-SCF states compared with the RI-JK approximation (Table S11, Supporting Information). This is likely related to inaccuracies associated to the integration grid required for the RIJCOSX approximation. Incorporation of dynamic correlation effects using $\mathrm{N}$-electron valence state perturbation theory (NEVPT2) ${ }^{90-92}$ also increases significantly the splitting of the ${ }^{2} \mathrm{~F}_{7 / 2}$ and ${ }^{2} \mathrm{~F}_{5 / 2}$ levels (Table S12, Supporting Information). Solvent effects (water, DMF, MeOH or DMSO) were incorporated with the SMD solvation model implemented in ORCA. ${ }^{93}$ Spin-orbit coupling effects were included by using quasi-degenerate perturbation theory (QDPT). ${ }^{94}$ The integration grid for $\mathrm{Yb}$ was increased from the default values (SpecialGridIntAcc 7).

\section{RESULTS AND DISCUSSION}

The structure of trivalent lanthanide ions in solution is determined by the size of the donating ligands and counter ions. The structure is in flux around a conformational minimum energy determined by a competition between the inter ligand repulsion and compensating the tri-positive charge of the lanthanide ion. The average structure is for small and simple ligands determined by the coordination number and the solution to the Thomson Problem associated with this number of donating point charges. Larger ligands impose other restraints due to their bulk. In this study, water and methanol belong to the class of small ligands, while the donor atoms of DMF and DMSO potentially carry enough bulk to change the coordination geometry and coordination number. This is expected to be significant here, as we study $\mathrm{Yb}^{3+}$, the second smallest trivalent lanthanide ion. The fully deuterated versions of water, $\mathrm{MeOH}$ and DMSO were used to increase the emission intensity. ${ }^{95,} 96$ Protonated DMF was used due to costs. The structure and electronic energy levels are not changed between protonated and deuterated solvents. ${ }^{61,62}$

We investigated solutions of $\mathrm{Yb}^{3+}$ made from the triflate salt, which is fully dissociated in these solvents at the concentrations used. ${ }^{61,62}$ The samples studied were solutions at room temperature, or frozen solutions at $77 \mathrm{~K}$. The latter were flash frozen.

The samples were not at the thermodynamic equilibrium, and they are expected to have the same variations in structure as the room temperature samples. The main difference between the room temperature and low temperature samples is due to the elimination of ligand exchange and the reduced population of higher energy electronic energy levels (microstates). Due to issues with scattering, absorption spectroscopy was only performed at room temperature. Luminescence emission and excitation spectra were recorded in both frozen solution at $77 \mathrm{~K}$ and at room temperature.

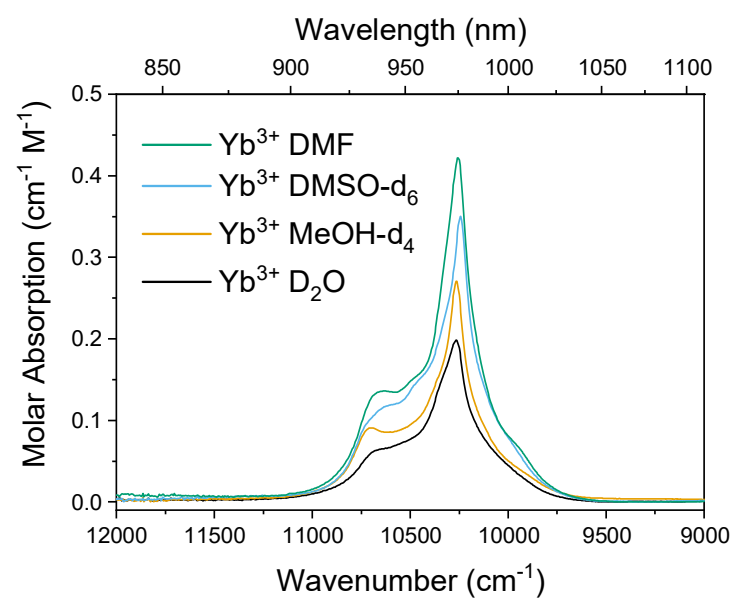

Figure 2. Absorption spectra of $\mathrm{Yb}\left(\mathrm{CF}_{3} \mathrm{SO}_{3}\right)_{3}$ in $\mathrm{D}_{2} \mathrm{O}, \mathrm{MeOH}-$ $\mathrm{d}_{4}$, DMSO- $\mathrm{d}_{6}$ and DMF.

Spectroscopy. Figure 2 shows the absorption spectra of $\mathrm{Yb}^{3+}$ in the investigated solvents. Light absorption is instantaneous (fs), and these spectra show: 1) that several complexes and/or conformations are present, as a smooth band is observed rather than distinct lines. ${ }^{97}$ And 2) that the total transition probability decreases from DMF, over DMSO and $\mathrm{MeOH}$ to water. The latter indicates that 
the average symmetry of the solvates increases along the series, as a coordination environments with higher symmetry around $\mathrm{Yb}^{3+}$ are expected to show a lower transition probability. ${ }^{27,}, 57,61-63,98$

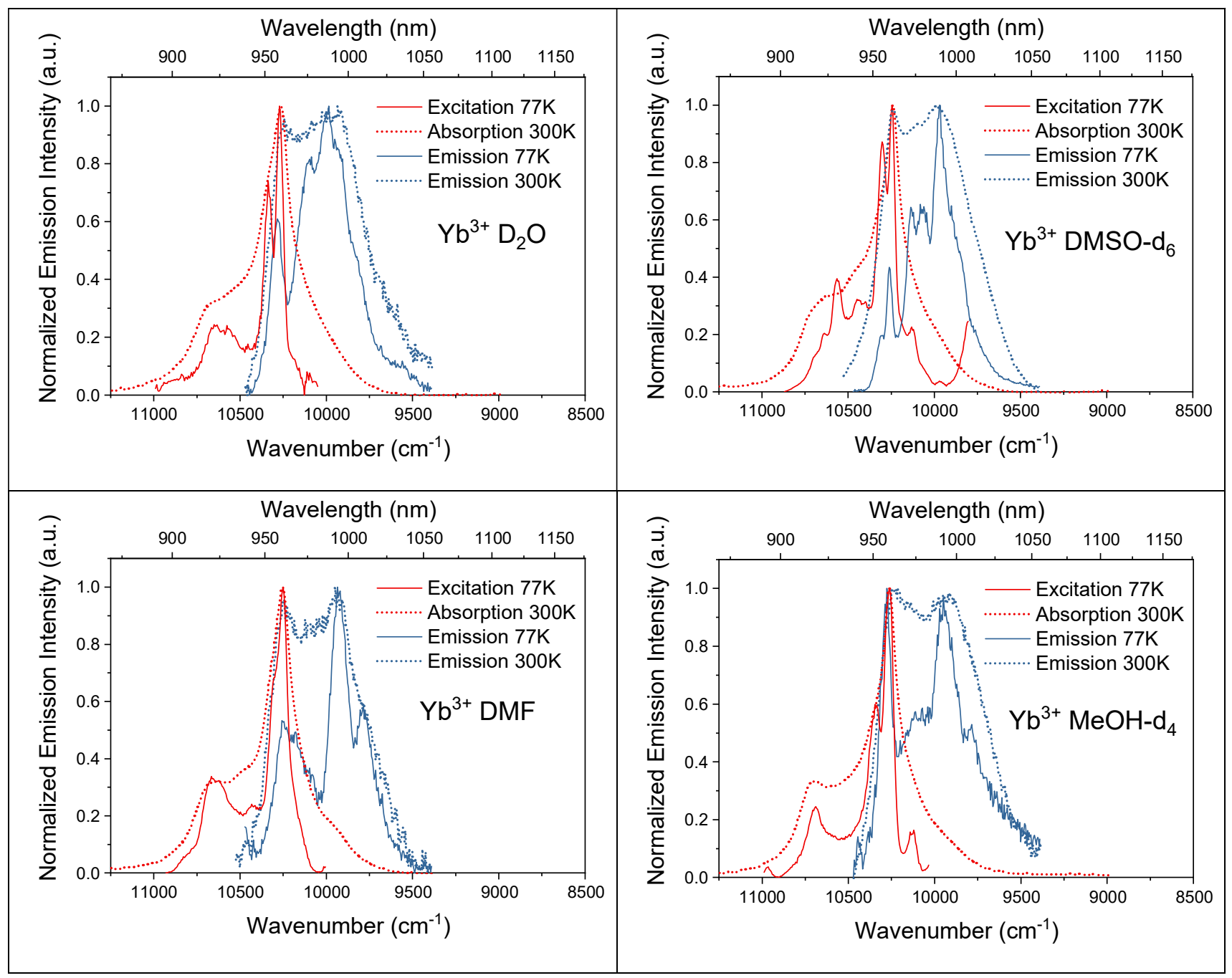

Figure 3. Absorption (300K), Excitation (77K) and Emission ( $77 \mathrm{~K}$ and $300 \mathrm{~K})$ spectra of $\mathrm{Yb}\left(\mathrm{CF}_{3} \mathrm{SO}_{3}\right)_{3}$ in $\mathrm{D}_{2} \mathrm{O}$ (top left), DMSO$\mathrm{d}_{6}$ (top right), DMF (bottom left) and $\mathrm{MeOH}-\mathrm{d}_{4}$ (bottom right).

Figure 3 shows the luminescence excitation and emission spectra. At $77 \mathrm{~K}$ the bands resolve into distinct lines. The excitation spectra are assumed to have 3 lines and the emission spectra should show 4 lines. Cursory inspection of the data shows that this is not the case.

Determining Electronic Energy Levels. To perform an experimental determination of the electronic energy levels of the solvates, we resolved the spectra using Lorentzian functions, see Supporting Information (Figure S34-41). A simpler, visual, assignment of the levels can be performed as shown in Figure 4. ${ }^{99}$ As each line is not clearly defined, we rely on fitting to assign the energy of each line of the spectrum, see the supporting information for details. The results from the fit are included in Tables S1-S2.
When considering the spectra in Figure 3, the difference between $300 \mathrm{~K}$ and $77 \mathrm{~K}$ is clear. In fluid solution there will be a number of structure fluctuations. ${ }^{23,26,100}$ In frozen solution these fluctuations are removed. It should be noted that since the $77 \mathrm{~K}$ samples are flash-frozen, the distribution of structures in the $300 \mathrm{~K}$ samples are expected to be maintained when frozen. The excited state lifetime of $\mathrm{Yb}^{3+}$ complexes is in the $\mu$ s range.$^{56,101}$ While short compared to the ms lifetimes of $\mathrm{Eu}^{3+}$ and $\mathrm{Tb}^{3+}$ this is still fast compared to the ligand exchange which occurs on the ns timescale. ${ }^{23}$ The consequence is that in fluid solution an excited $\mathrm{Yb}^{3+}$ ion will undergo several different conformations and structure changes before emission occurs. This contributes to the shape and broadening of the spectra. ${ }^{27}$ 
The Boltzmann population of the microstates also influences the observed spectra. Considering a two state model, the energy at which the higher lying excited state has a $1 \%$ population is approximately 4 times the Boltzmann constant times the absolute temperature. This energy is $214 \mathrm{~cm}^{-1}$ at $77 \mathrm{~K}$ and $834 \mathrm{~cm}^{-1}$ at $300 \mathrm{~K}$. We estimate that any transitions occurring from higher lying states with a thermal population of less than $10 \%$ will not be detectable. This is illustrated in Figure 4. Therefore, we assign the main transitions in the $77 \mathrm{~K}$ spectra as transitions occurring from the lowest lying microstate.

While the electronic energy levels could be determined experimentally, they cannot be assigned to a structure, and we are not able to assign all the lines we see in the resolved spectra. Thus, we turned our attention to theory.

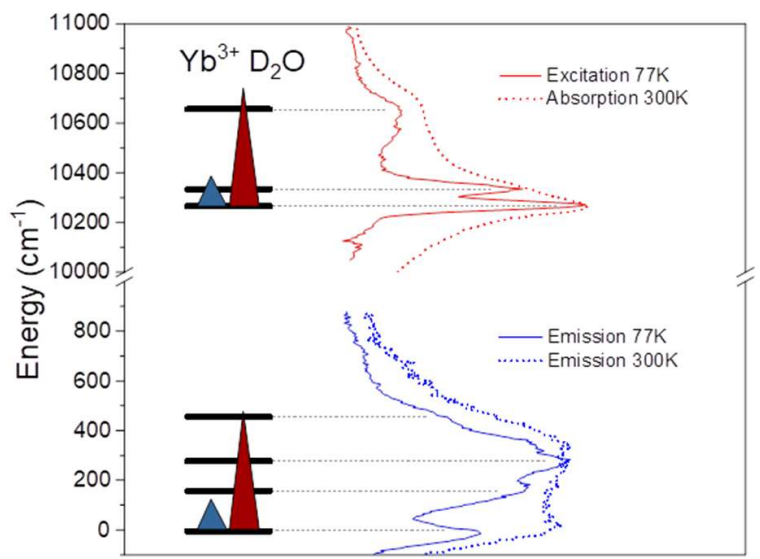

Figure 4. Experimentally determined electronic structure of $\mathrm{Yb}\left(\mathrm{CF}_{3} \mathrm{SO}_{3}\right)_{3}$ in $\mathrm{D}_{2} \mathrm{O}$. Ground state levels were determined from emission spectra, excited state levels were determined from excitation spectra. Dashed lines indicate peaks on spectra. Triangles indicate the Boltzmann distribution at $77 \mathrm{~K}$ (blue) and $300 \mathrm{~K}$ (red). The top of the triangles is set at a $10 \%$ population.

The $\mathrm{Yb}^{3+}$ hydrate. The structures of the $\left[\mathrm{Yb}\left(\mathrm{H}_{2} \mathrm{O}\right)_{8}\right]^{3+}$ and $\left[\mathrm{Yb}\left(\mathrm{H}_{2} \mathrm{O}\right)_{9}\right]^{3+}$ complexes were obtained using DFT calculations. These calculations provided the expected energy minima with square antiprismatic $(q=8)$ and tricapped trigonal prismatic $(q=9)$ geometries, which show slightly distorted $S_{8}$ and $D_{3 \mathrm{~h}}$ symmetries, respectively. The calculated bond distances of the metal coordination environments are compared with experimental data obtained with $X$-ray diffraction measurements in the solid state and EXAFS and neutron diffraction measurements in solution. The $\left[\mathrm{Yb}\left(\mathrm{H}_{2} \mathrm{O}\right)_{9}\right]^{3+}$ complex presents two different $\mathrm{Yb}-\mathrm{O}$ bond distances, with those involving capping donor atoms being somewhat longer, as would be expected, see Table 1.

Table 1. Yb-O distances $(\AA)$ obtained with DFT calculations and comparison with experimental data. ${ }^{a}$

$\begin{array}{llll} & \mathrm{Yb}-\mathrm{Oax} & \mathrm{Yb}-\mathrm{O} \text { eq } & \text { Exp. } \\ {\left[\mathrm{Yb}\left(\mathrm{H}_{2} \mathrm{O}\right)_{8}\right]^{3+}} & 2.382 & - & 2.328^{102-104} \\ {\left[\mathrm{Yb}\left(\mathrm{H}_{2} \mathrm{O}\right)_{8}\right]^{3+} \cdot 19 \mathrm{H}_{2} \mathrm{O}} & 2.343 & - & 2.324^{105} \\ {\left[\mathrm{Yb}\left(\mathrm{H}_{2} \mathrm{O}\right)_{9}\right]^{3+}} & 2.414 & 2.456 & \end{array}$

$\begin{array}{llll}{\left[\mathrm{Yb}\left(\mathrm{H}_{2} \mathrm{O}\right)_{9}\right]^{3+} \cdot 18 \mathrm{H}_{2} \mathrm{O}} & 2.357 & 2.483 & \begin{array}{l}2.321 \\ 2.518 \\ (\mathrm{eq})^{106}\end{array} \\ & & & - \\ {[\mathrm{Yb}(\mathrm{MeOH})} & \\ {\left[\mathrm{Yb}(\mathrm{DMF})_{8}\right]^{3+}} & 2.392 & & 2.293(47) \\ & 2.373(39 & & \\ {\left[\mathrm{Yb}(\mathrm{DMSO})_{8}\right]^{3+}} & ) & & 2.332(37) \\ & 2.378(41 & - & \\ {\left[\mathrm{Yb}(\mathrm{DMSO})_{7}\right]^{3+}} & 2.287(2) & 2.333(12) & 2.227(5) \\ & & & 2.276(19)^{73}\end{array}$

a Standard deviations are provided within parentheses.

The $\mathrm{Yb}-\mathrm{O}$ distances calculated for the $\left[\mathrm{Yb}\left(\mathrm{H}_{2} \mathrm{O}\right)_{8}\right]^{3+}$ system $(2.382 \AA)$ is somewhat longer than those determined in the solid state using X-ray diffraction, or in solution with neutron diffraction and EXAFS (2.32-2.33 $\AA$ ) measurements. The structure of the $\left[\mathrm{Yb}\left(\mathrm{H}_{2} \mathrm{O}\right)_{9}\right]^{3+}$ system also shows $\mathrm{Yb}-\mathrm{O}$ distances somewhat longer than those observed in the solid state (Table 1), both for the axial and equatorial water molecules (equatorial water molecules occupy capping positions). The calculated distances are in very good agreement with those computed previously using B3LYP and the small core approximation (2.38 and $2.43 \AA$ for $\left[\mathrm{Yb}\left(\mathrm{H}_{2} \mathrm{O}\right)_{8}\right]^{3+}$ and $\left[\mathrm{Yb}\left(\mathrm{H}_{2} \mathrm{O}\right)_{9}\right]^{3+}$, respectively. ${ }^{107}$

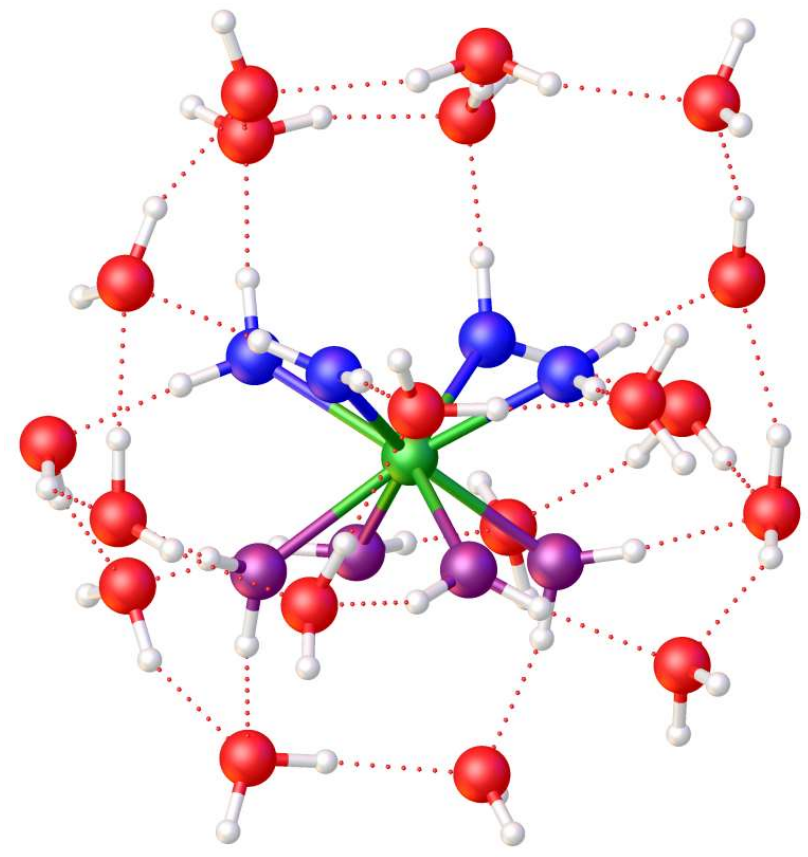

Figure 5. Structure of the $\left[\mathrm{Yb}\left(\mathrm{H}_{2} \mathrm{O}\right)_{8}\right]^{3+} \cdot 19 \mathrm{H}_{2} \mathrm{O}$ cluster obtained with DFT calculations. Oxygen atoms of secondsphere water molecules are shown in red. The square antiprismatic coordination environment is highlighted by using different colors for the oxygen atoms of the upper (blue) and lower (magenta) square faces.

Previous studies showed that the inclusion of explicit second-sphere water molecules provoke an important shortening of the distances between the metal ion and the oxygen atom of coordinated water molecules in lanthanide complexes, ${ }^{108,} 109$ including $\mathrm{Yb}^{3+}$ derivatives. ${ }^{110}$ These second-sphere water molecules are involved in hydrogen 
bonds with coordinated water molecules, polarizing the $\mathrm{O}-\mathrm{H}$ bonds of coordinated water molecules. Thus, we performed calculations on the $\left[\mathrm{Yb}\left(\mathrm{H}_{2} \mathrm{O}\right)_{9}\right]^{3+} \cdot 18 \mathrm{H}_{2} \mathrm{O}$ system, which contains two explicit second-sphere water molecules acting as hydrogen-bond acceptors for each of the inner-sphere waters, see Figure S50. Subsequently, a second energy minima containing eight coordinated water molecules was located by exploring the potential energy surface $\left(\left[\mathrm{Yb}\left(\mathrm{H}_{2} \mathrm{O}\right)_{8}\right]^{3+} \cdot 19 \mathrm{H}_{2} \mathrm{O}\right)$, see Figure 5.
Similar hydrogen bonding patterns involving first- and second-sphere water molecules were found for clusters involving six-coordinated metal ions. ${ }^{111,112}$ The inclusion of explicit second-sphere water molecules causes a significant decrease of the calculated $\mathrm{Yb}-\mathrm{O}$ distances, which approach the experimental values, see Table 1. 


\begin{tabular}{|c|c|c|c|c|c|c|}
\hline \multirow[t]{13}{*}[\mathrm{Yb}(\mathrm{H}_{2}\mathrm{O})9]{$^{3+} \cdot 18 \mathrm{H}_{2} \mathrm{O}$} & Transition (pop.) $)^{a}$ & Energy $\left(\mathrm{cm}^{-1}\right)$ & $10^{9} \times f_{\text {osc }}$ & $\operatorname{Exp}(\text { exc. })^{b}$ & $\begin{array}{l}\text { Exp } \\
(\mathrm{em} .)^{c}\end{array}$ & $\Delta$ Calc,Exp \\
\hline & $4 \leftarrow 0(0.341 ; 0.563)$ & 10257.0 & 210 & 10268 & 10288 & $-11 /-31$ \\
\hline & $5 \leftarrow 0(0.341 ; 0.563)$ & 10317.1 & 54 & 10337 & 10312 & $-19.9 /-5.1$ \\
\hline & $6 \leftarrow 0(0.341 ; 0.563)$ & 10384.4 & 244 & 10658 & & -273.6 \\
\hline & $4 \leftarrow 1(0.295 ; 0.323)$ & 10227.3 & 206 & & 10116 & 111.3 \\
\hline & $5 \leftarrow 1(0.295 ; 0.323)$ & 10287.5 & 196 & & & \\
\hline & $6 \leftarrow 1(0.295 ; 0.323)$ & 10354.7 & 2 & 10564 & & 209.3 \\
\hline & $4 \leftarrow 2(0.212 ; 0.089)$ & 10158.5 & 22 & & 9998 & 160.5 \\
\hline & $5 \leftarrow 2(0.212 ; 0.089)$ & 10218.6 & 2 & & & \\
\hline & $6 \leftarrow 2(0.212 ; 0.089)$ & 10285.9 & 74 & & & \\
\hline & $4 \leftarrow 3(0.152 ; 0.025)$ & 10089.9 & 8 & & 9818 & 271.9 \\
\hline & $5 \leftarrow 3(0.152 ; 0.025)$ & 10150.0 & 64 & & & \\
\hline & $6 \leftarrow 3(0.152 ; 0.025)$ & 10217.3 & 2 & & & \\
\hline \multirow[t]{13}{*}[\mathrm{Yb}(\mathrm{H}_{2}\mathrm{O})_{8}]{$^{3+\cdot} \cdot 19 \mathrm{H}_{2} \mathrm{O}$} & Transition (pop.) & Energy $\left(\mathrm{cm}^{-1}\right)$ & $10^{9} \times f_{\text {osc }}$ & $\operatorname{Exp}(\text { exc. })^{b}$ & $\begin{array}{l}\text { Exp } \\
(\mathrm{em} .)^{c}\end{array}$ & $\Delta$ Calc,Exp \\
\hline & $4 \leftarrow 0(0.445 ; 0.679)$ & 10274.3 & 490 & 10268 & 10288 & $6.3 /-13.7$ \\
\hline & $5 \leftarrow 0(0.445 ; 0.679)$ & 10362.3 & 214 & 10337 & 10312 & $25.3 / 50.3$ \\
\hline & $6 \leftarrow 0(0.445 ; 0.679)$ & 10614.4 & 62 & 10658 & & -43.6 \\
\hline & $4 \leftarrow 1(0.366 ; 0.317)$ & 10233.6 & 124 & & 10116 & 117.6 \\
\hline & $5 \leftarrow 1(0.366 ; 0.317)$ & 10321.6 & 310 & & & \\
\hline & $6 \leftarrow 1(0.366 ; 0.317)$ & 10573.7 & 80 & 10564 & & 9.7 \\
\hline & $4 \leftarrow 2(0.117 ; 0.004)$ & 9996.9 & 44 & & 9998 & -1.1 \\
\hline & $5 \leftarrow 2(0.117 ; 0.004)$ & 10084.8 & 36 & & & \\
\hline & $6 \leftarrow 2(0.117 ; 0.004)$ & 10336.9 & 0 & & & \\
\hline & $4 \leftarrow 3(0.073 ; 0.000)$ & 9898.8 & 2 & & 9818 & 80.8 \\
\hline & $5 \leftarrow 3(0.073 ; 0.000)$ & 9986.7 & 2 & & & \\
\hline & $6 \leftarrow 3(0.073 ; 0.000)$ & 10238.8 & 0 & & & \\
\hline
\end{tabular}

a Populations of the lower energy level involved in the transition at 300 and $77 \mathrm{~K} .{ }^{\mathrm{b}}$ Experimental data obtained from the analysis of the excitation spectra. ${ }^{c}$ Experimental data obtained from emission spectra.

CASSCF/QDPT calculations were used to investigate the splitting of the ${ }^{2} \mathrm{~F}$ manifold as a result of spin-orbit and crystal field effects. The results are tabulated in Table 2 for the aqua ions and Tables S13-S14 for the remaining solvates. As an initial analysis of the computed data, we investigate the total splitting of the microstates in the ${ }^{2} \mathrm{~F}_{7 / 2}$ and ${ }^{2} \mathrm{~F}_{5 / 2}$ terms by the crystal field of the aqua ligands, see Figure 1. For the $\left[\mathrm{Yb}\left(\mathrm{H}_{2} \mathrm{O}\right)_{8}\right]^{3+}(\mathrm{CN} 8)$ and $\left[\mathrm{Yb}\left(\mathrm{H}_{2} \mathrm{O}\right)_{9}\right]^{3+}$ (CN 9) systems we find a larger splitting of both levels in the former. The total crystal field splitting of the ground and excited states calculated for $\left[\mathrm{Yb}\left(\mathrm{H}_{2} \mathrm{O}\right)_{9}\right]^{3+}$ are 187.2 and $128.9 \mathrm{~cm}^{-1}$, while the corresponding values for $\left[\mathrm{Yb}\left(\mathrm{H}_{2} \mathrm{O}\right)_{8}\right]^{3+}$ are 300.4 and $252.5 \mathrm{~cm}^{-1}$. As a result, the energy difference between the lowest and highest energy levels amount to 10408 and $10546 \mathrm{~cm}^{-1}$ for $\left[\mathrm{Yb}\left(\mathrm{H}_{2} \mathrm{O}\right)_{9}\right]^{3+}$ and $\left[\mathrm{Yb}\left(\mathrm{H}_{2} \mathrm{O}\right)_{8}\right]^{3+}$, respectively. The experimental absorption spectrum presents a component on the high-energy side at $10658 \mathrm{~cm}^{-1}$, suggesting that $\mathrm{Yb}^{3+}$ is coordinated by eight water molecules in solution.

The inclusion of a second-sphere hydration shell reduces the overall splitting of $\left[\mathrm{Yb}\left(\mathrm{H}_{2} \mathrm{O}\right)_{9}\right]^{3+} \cdot 18 \mathrm{H}_{2} \mathrm{O}$ to $10384 \mathrm{~cm}^{-1}$, while for the eight-coordinated species increases to $10614 \mathrm{~cm}^{-1}$. The latter value is very close to the experimental one. Furthermore, the energy levels calculated for the $\left[\mathrm{Yb}\left(\mathrm{H}_{2} \mathrm{O}\right)_{8}\right]^{3+} \cdot 19 \mathrm{H}_{2} \mathrm{O}$ cluster match very well the experimental absorption spectrum. 

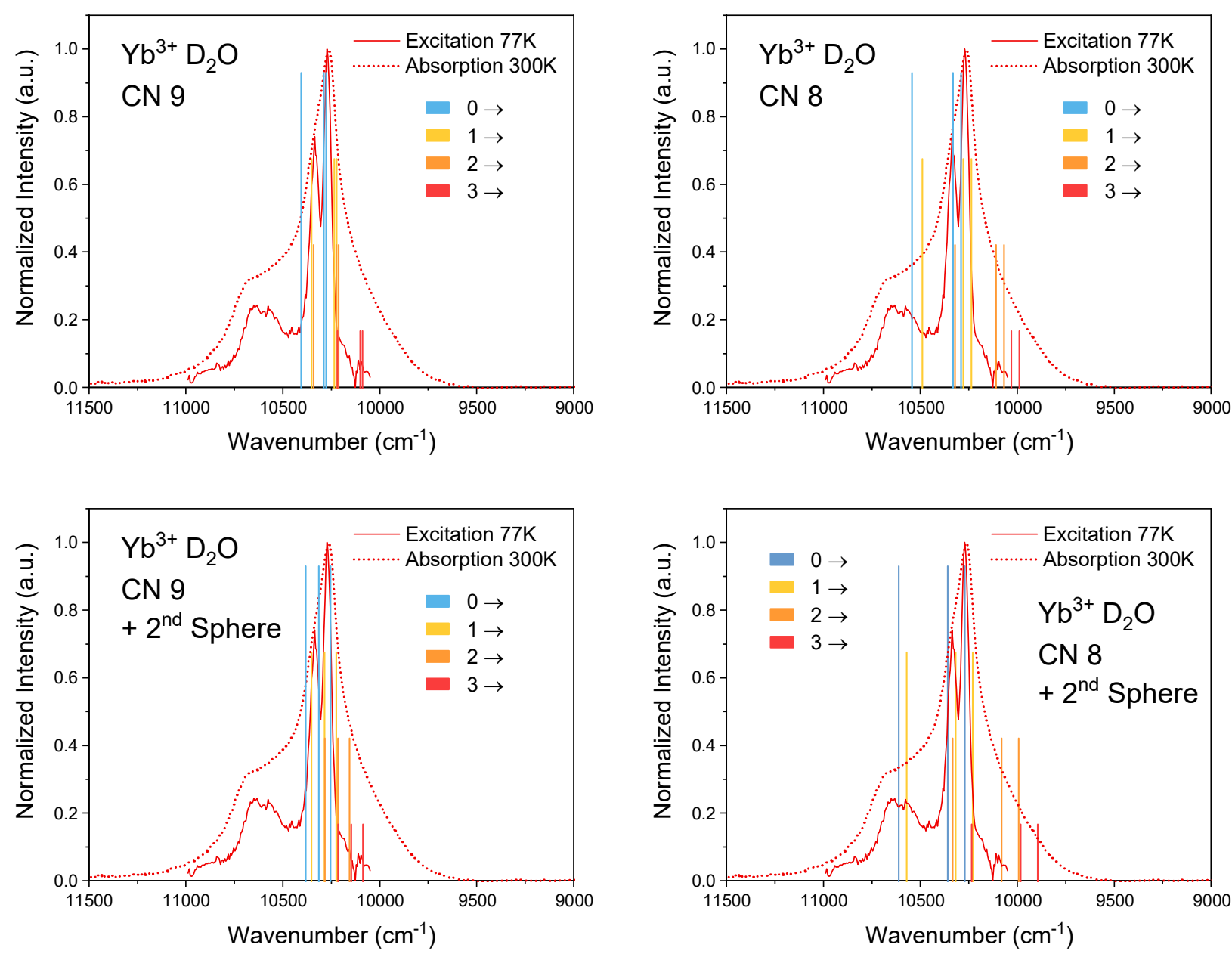

Figure 6. Absorption (300K) and Excitation (77K) spectra of $\mathrm{Yb}\left(\mathrm{CF}_{3} \mathrm{SO}_{3}\right)_{3}$ in $\mathrm{D}_{2} \mathrm{O}$ with calculated transitions of $\left[\mathrm{Yb}\left(\mathrm{H}_{2} \mathrm{O}\right)_{9}\right]^{3+}$ (top left), $\left[\mathrm{Yb}\left(\mathrm{H}_{2} \mathrm{O}\right)_{8}\right]^{3+}$ (top right), and with the second solvent sphere (bottom left + bottom right). Lines are scaled as 1, 0.7, 0.4 and 0.1 for the first (blue), second (yellow), third (orange) and fourth (red) microstate respectively to illustrate the expected intensity based on thermal population. All intrinsic transition probabilities are set to 1.

The initial analysis of the computational results indicates that the experimental data arise from a $\left[\mathrm{Yb}\left(\mathrm{H}_{2} \mathrm{O}\right)_{8}\right]^{3+} \mathrm{com}-$ plex with a square antiprismatic structure. All experimental and computed data is given in Table 2 for the aqua ions and Tables S13-S14 for the remaining solvates, but it is all but impossible to make conclusions based on the tabulated matter. In particular, as transition probabilities, Boltzmann distributions and sample heterogeneity has to be taken into account. Thus we turn to a visual comparison, similar to what we have done previously for dysprosium(III) and what is shown in Figure $4 .{ }^{61}$

By using a direct visual comparison between experimental data and calculated energy levels, we can determine if the computed structure is identical to the solution structure of the complexes. The analysis for the $\mathrm{Yb}^{3+}$ hydrate is shown in Figure 6. Computed transition energies are plotted directly on the spectra scaled with an arbitrary Boltzmann distribution. This ensures that the transitions from the lowest lying energy levels carries a higher significance than transitions from energy levels with little or no thermal populations, see Figure 4 . Inspection shows that
$\left[\mathrm{Yb}\left(\mathrm{H}_{2} \mathrm{O}\right)_{8}\right]^{3+}(\mathrm{CN} 8)$ provides a significantly better fit between experiment and theory than the $\left[\mathrm{Yb}\left(\mathrm{H}_{2} \mathrm{O}\right)_{9}\right]^{3+}(\mathrm{CN} 9)$ structure. Including the second sphere corrections improves the CN 8 to a satisfactory level while the CN 9 remains a poor fit.

The same trend can be seen for the emission spectra and the transitions from the ${ }^{2} \mathrm{~F}_{5 / 2}$ manifold, see Figures S16S23. In these comparisons we have scaled the calculated transition intensities by an arbitrary Boltzmann population. However, this treatment ignores any differences in the intrinsic transition probability between individual microstates - differences that theory predicts to be significant. While the theoretical calculations provide transition probabilities, their accuracy remains unclear. Figure S7S10 shows a representation where the calculated transitions are scaled by the calculated transition probabilities. These results show a good agreement between experiment and theory for the transition probabilities found in the absorption/excitation spectra, but the transition probabilities observed in the emission spectra do not match those found in the calculations. 
Several other methods of comparing experimental and computational results were tested, but we returned to the simple representation shown in Figure 6 . For the $\mathrm{Yb}^{3+}$ hydrate it is also convincing to simply plot the experimentally determined electronic energy levels next to those calculated for $\left[\mathrm{Yb}\left(\mathrm{H}_{2} \mathrm{O}\right)_{9}\right]^{3+}$ and $\left[\mathrm{Yb}\left(\mathrm{H}_{2} \mathrm{O}\right)_{8}\right]^{3+}$ with the second sphere solvent, see Figure 7. Cursory inspection of Figure 7 gives rise to the same conclusion as the detailed analysis in Figure 6 and the band gap considerations done above. Do note that the simple picture in Figure 7 may be misleading, and the match between calculated electronic energy levels cannot stand alone. The transition energies must be compared to the spectra in a plot similar to that done in Figure 6.

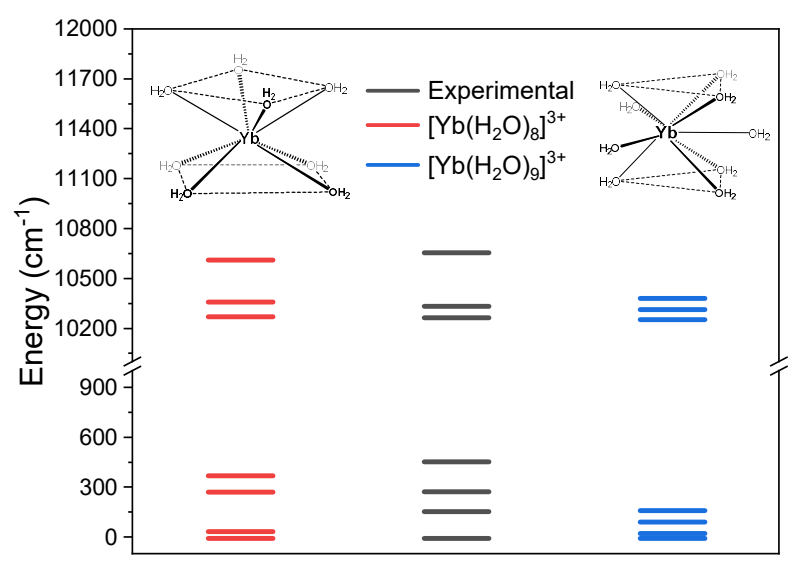

Figure 7. Calculated energy levels of $\left[\mathrm{Yb}\left(\mathrm{H}_{2} \mathrm{O}\right)_{8}\right]^{3+}$ (red, left) and $\left[\mathrm{Yb}\left(\mathrm{H}_{2} \mathrm{O}\right)_{9}\right]^{3+}$ (blue, right) with experimentally determined energy levels of $\mathrm{Yb}\left(\mathrm{CF}_{3} \mathrm{SO}_{3}\right)_{3}$ in $\mathrm{D}_{2} \mathrm{O}$ (black, center). Excited state levels were determined from absorption and excitation spectra, ground state levels were determined from emission spectra.

The other $\mathrm{Yb}^{3+}$ solvates. Using the procedure outlined above, we can assign the structure of the remaining solvates. The optical spectra of the methanol and DMF solvates fits well with a CN 8 square antiprismatic structure, see Figures S30-S33. It should be noted that neither the experimental data nor the calculations are of the same quality as for the aqua ion.

For the DMSO solvate, the experimental data indicate a much larger number of transitions, than in the other solvates. Comparing to the computational data we see that a single structure is insufficient to account for the number of transitions observed. This is illustrated in Figure 8. Here, we compare the calculated transition energies for the $\mathrm{CN}$ 7 and CN 8 structures to the observed spectra. Neither of the calculated structures account for the full spectra, but if we assume the sample contains both structures, we can account for all the observed bands in the spectra. An observation we rationalize by concluding that an equilibrium between the two structures exist in solution. This is also consistent with the relative bulk of DMSO compared to water. The structural difference is evidently enough to cause a change in coordination number. ${ }^{61}$ 


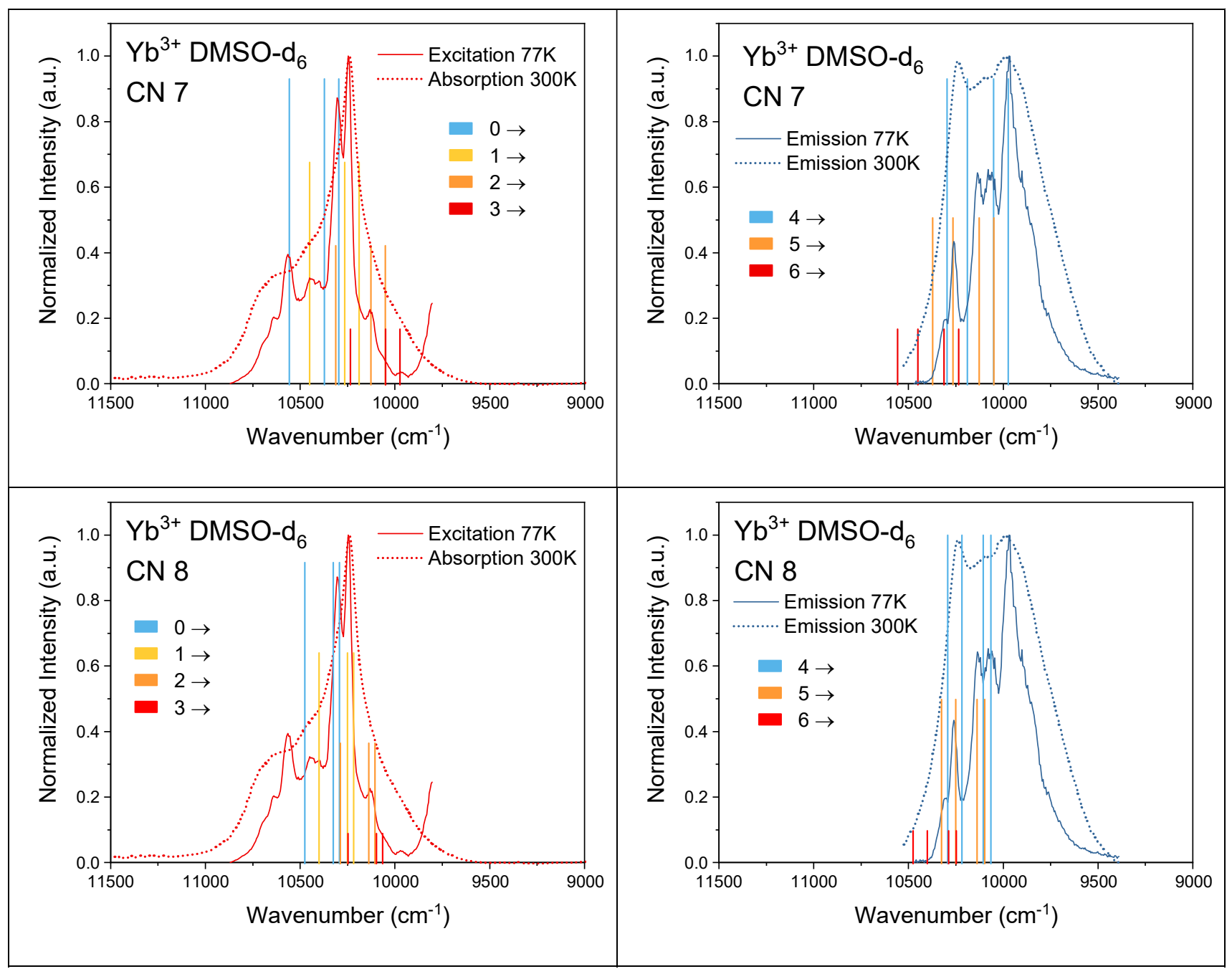

Figure 8. Absorption (300K), Excitation (77K) and Emission (300K and $77 \mathrm{~K})$ spectra of $\mathrm{Yb}\left(\mathrm{CF}_{3} \mathrm{SO}_{3}\right)_{3}$ in DMSO-d 6 with calculated transitions of $\left[\mathrm{Yb}(\mathrm{DMSO})_{7}\right]^{3+}$ (top) and $\left[\mathrm{Yb}(\mathrm{DMSO})_{7}\right]^{3+}$ (bottom) shown as lines. Lines are scaled as $1,0.7,0.4$ and 0.1 for the first (blue), second (yellow), third (orange) and fourth (red) microstate respectively for absorption and excitation (left) and as 1 , 0.5 , and 0.1 for the first (blue), second (orange) and third (red) for emission (left) to illustrate the expected intensity based on thermal population. All intrinsic transition probabilities are set to 1.

Solution Structure and Ligand Field Splitting. To reiterate, the optical spectra of the four solvates is well represented by a single - in the case of DMSO two - $\mathrm{Yb}^{3+}$ complexes. The spectra represent transitions between the seven electronic energy levels or microstates of the $\mathrm{Yb}^{3+}$ ion, which are compared to state of the art computational data. From the experimental data the energy levels can be determined directly, as shown in Figure 4, or by resolving the lines of the spectra using numerical methods, as shown in Figure S34-S41.

Based on computational data, we can assign the solution structure, which in turn allows us to compare the experimentally determined energy levels with the calculated energy levels. Figure 7 shows the case of water. While the calculated energy levels of the CN 8 fit nicely with the experimentally determined energy levels, the CN 9 structure does not fit in neither the ${ }^{2} \mathrm{~F}_{7 / 2}$ nor ${ }^{2} \mathrm{~F}_{5 / 2}$ manifold. Thus we assign the experimentally observed spectra of
$\mathrm{Yb}\left(\mathrm{CF}_{3} \mathrm{SO}_{3}\right)_{3}$ dissolved in water to the $\left[\mathrm{Yb}\left(\mathrm{H}_{2} \mathrm{O}\right)_{8}\right]^{3+}$ complex with a square anti-prismatic coordination geometry. A very recent computational and EXAFS study on the $\mathrm{Er}^{3+}$ aqua ion concluded that the coordination sphere is rather fluxional, with the square antiprismatic coordination being the most probable one. ${ }^{113}$ Our results are in good agreement with these results. The agreement between experimental and calculated data improves considerably upon inclusion of a second solvation shell, which distorts the square antiprismatic coordination environment, likely in a similar way as the dynamic processes occurring in solution.

Similarly, we can conclude that the main species of $\mathrm{Yb}^{3+}$ in $\mathrm{MeOH}$ and $\mathrm{DMF}$ are the $\left[\mathrm{Yb}(\mathrm{MeOH})_{8}\right]^{3+}$ and $\left[\mathrm{Yb}(\mathrm{DMF})_{8}\right]^{3+}$ species respectively, both with a square anti-prismatic coordination geometry.

For the DMSO case the picture is less clear. However, it is important to note that the experimentally determined 
energy levels have been found with the assumption of only one dominant species being present in solution. As we have no way of distinguishing which transitions come from a specific species using experimental data alone, no such attempt was made and simply we conclude that $\mathrm{Yb}^{3+}$ in DMSO is a mixture of $\left[\mathrm{Yb}(\mathrm{DMSO})_{8}\right]^{3+}$ and $\left[\mathrm{Yb}(\mathrm{DMSO})_{7}\right]^{3+}$ in a square anti-prismatic and pentagonal bipyramid coordination geometry, respectively.

While no further analysis is possible for the $\mathrm{Yb}^{3+}$ solvate in DMSO, the three other solvates appear to be all pure solvates with coordination number (CN) 8 and a square anti-prismatic coordination geometry. This allows us to explore the ligand field splitting of these complexes, and compare to the spin-orbit coupling, using experimentally determined data. We observe clear differences in both ligand field splitting and line widths, see Supporting Information, in what we assume is three donor sets that comprise eight oxygen atoms and nominally have the same coordination geometry. This is evident in the spectra in Figure 3 , and can be seen by scrutinizing the numbers in Tables S13-S14. While the data from DMF and methanol do merit further investigation, the data from water are of a quality, see Figure 4, that allows us to quantify. As all textbooks prescribe, the spin orbit splitting of $\mathrm{Yb}^{3+}$ is at 10,000 $\mathrm{cm}^{-1}$, two orders of magnitude larger than crystal field splitting, which is on the order of $\sim 200 \mathrm{~cm}^{-1}$. While minute changes in the nature of the donor atoms and coordination geometry are clearly evident, our current level of theory clearly differentiates between the structures that could be present in solution, see Figure 7 .

\section{CONCLUSION}

We can conclude that we have reached the point that the theoretical description of $\mathrm{Yb}^{3+}$ allows calculating the full ladder of electronic energy levels-microstates-at a level that it allows us to differentiate between different solution structures. Following the methodology described here, where we combine optical spectroscopy and computational chemistry, we demonstrated that it is possible to differentiate between both coordination numbers and coordination geometries.

Our results confirm a coordination number of eight and a square anti-prismatic coordination geometry for $\mathrm{Yb}^{3+}$ solvates in water, methanol, and DMF. We believe that this is the first example, where computational results directly confirm solution structures, without clear support from the solid state structures. Further, the method was able to reveal a complicated speciation in DMSO, where two different $\mathrm{Yb}^{3+}$ solvates with coordination numbers seven and eight are present.

Finally, we can conclude that even among complexes as similar as the solvates investigated here, minute changes in the ligand field translates into differences in optical spectra that are readily determined. The obvious next step is to see if we can use the methods to investigate complexes and to move to trivalent lanthanide ions with a more complicated electronic structure.

\section{SUPPORTING INFORMATION.}

The following files are available free of charge:
The supporting information contains all optical spectra fits of spectra and fit parameters, determined energy levels, spectral and computational overlays, optimized Cartesian coordinates and sample ORCA input file. 


\section{Corresponding Author}

*Thomas Just Sørensen, tjs@chem.ku.dk, @f_elements, Nano-Science Center and Department of Chemistry, University of Copenhagen, Universitetsparken 5, 2100 København $\varnothing$, Denmark.

* Carlos Platas Iglesias, carlos.platas.iglesias@udc.es, Centro de Investigacións Científicas Avanzadas and Departamento de Química, Universidade da Coruña, Campus da Zapateira-Rúa da Fraga 10, 15008 A Coruña, Spain.

\section{Funding Sources}

We thank Carlsbergfondet, Villum Fonden (grant\#14922), and the University of Copenhagen for funding.

\section{ACKNOWLEDGMENT}

T. J. S. \& N. K. thank Carlsbergfondet, Villum Fonden (grant\#14922), and the University of Copenhagen for support. N. K. also thank the Danish Chemical Society and Fulbright Denmark for support. C. P.-I. thanks Centro de Supercomputación de Galicia (CESGA) for providing the computer facilities. We thank Niels Andreas Bonde, University of Copenhagen, for help during the preparation of the manuscript.

\section{REFERENCES}

\section{$1 . \quad$ Laboratory, N. E. T.}

https://www.netl.doe.gov/coal/rare-earth-elements/programoverview/background?fbclid=IwAR2A44qKyqEHDWylWUXMqy6LPr1snFGK96P1N9CXyB 2jcpZghYmZ-rBo.

2. King, A. H.; Eggert, R. G.; Gschneidner Jr, K. A. The rare earths as critical materials. In Handbook on the Physics and Chemistry of Rare Earths, Elsevier: 2016; Vol. 50, pp 19-46.

3. Strnat, K. J.; Strnat, R. M. W., Rare earth-cobalt permanent magnets. Journal of Magnetism and Magnetic Materials 1991, 100 (1), 38-56.

4. Kumar, K., RETM5 and RE2TM17 permanent magnets development. Journal of Applied Physics 1988, 63 (6), R13-R57.

5. Kurima, K.; Satoshi, H., Chapter 208 Permanent magnets. In Handbook on the Physics and Chemistry of Rare Earths, Elsevier: 2001; Vol. 32, pp 515-565.

6. Vereb, G.; Jares-Erijman, E.; Selvin, P. R.; Jovin, T. M., Temporally and Spectrally Resolved Imaging Microscopy of Lanthanide Chelates. Biophysical Journal 1998, 74 (5), 2210-2222.

7. Hemmilä, I.; Dakubu, S.; Mukkala, V.-M.; Siitari, H.; Lövgren, T., Europium as a label in time-resolved immunofluorometric assays. Analytical Biochemistry 1984, 137 (2), 335-343.

8. Nybro Dansholm, C.; Junker, A. K. R.; Nielsen, L. G.; Kofod, N.; Pal, R.; Sørensen, T. J., ח-Expanded Thioxanthones-Engineering the Triplet Level of Thioxanthone Sensitizers for Lanthanide-Based Luminescent Probes with Visible Excitation.

ChemPlusChem 2019, 84 (12), 1777-1777.

9. Caravan, P.; Ellison, J. J.; McMurry, T. J.; Lauffer, R. B., Gadolinium(III) chelates as MRI contrast agents: Structure, dynamics, and applications. Chem Rev 1999, 99 (9), 2293-2352.

10. Sherry, A. D.; Caravan, P.; Lenkinski, R. E., Primer on Gadolinium Chemistry. Journal of Magnetic Resonance Imaging 2009, 30 (6), 1240-1248.
11. Sørensen, M. A.; Hansen, U. B.; Perfetti, M Pedersen, K. S.; Bartolomé, E.; Simeoni, G. G.; Mutka, H.; Rols, S.; Jeong, M.; Zivkovic, I.; Retuerto, M.; Arauzo, A.; Bartolomé, J.; Piligkos, S.; Weihe, $H_{\text {.; }}$ Doerrer, L. H.; van Slageren, J.; Rønnow, H. M.; Lefmann, $\mathrm{K}$.; Bendix, J., Chemical tunnel-splitting-engineering in a dysprosium-based molecular nanomagnet. Nature Communications 2018, 9 (1), 1292.

12. Goodwin, C. A. P.; Reta, D.; Ortu, F.; Chilton, N. F.; Mills, D. P., Synthesis and Electronic Structures of Heavy Lanthanide Metallocenium Cations. Journal of the American Chemical Society 2017, 139 (51), 18714-18724. 13. Luzon, J.; Sessoli, R., Lanthanides in molecular magnetism: so fascinating, so challenging. Dalton Transactions 2012, 41 (44), 13556-13567.

14. Sessoli, R.; Powell, A. K., Strategies towards single molecule magnets based on lanthanide ions. Coordination Chemistry Reviews 2009, 253 (19), 23282341.

15. Arppe, R.; Sørensen, T. J., Physical unclonable functions generated through chemical methods for anticounterfeiting. Nature Reviews Chemistry 2017, 1 (4), 0031. 16. Energy, U. S. D. o. Critical Materials Strategy 2011.

17. Ekberg, C.; Fermvik, A.; Retegan, T.;

Skarnemark, G.; Foreman, M.; Hudson, M.; Englund, S.; Nilsson, M. J. R. A., An overview and historical look back at the solvent extraction using nitrogen donor ligands to extract and separate An (III) from Ln (III). 2008, 96 (4-5), 225-233.

18. Nelson, J. J.; Schelter, E. J., Sustainable inorganic chemistry: metal separations for recycling. Inorganic Chemistry 2019.

19. Tunsu, C.; Petranikova, M.; Gergorić, M.; Ekberg, C.; Retegan, T. J. H., Reclaiming rare earth elements from end-of-life products: A review of the perspectives for urban mining using hydrometallurgical unit operations. Hydrometallurgy 2015, 156, 239-258.

20. Yang, Y.; Walton, A.; Sheridan, R.; Güth, K.; Gauß, R.; Gutfleisch, O.; Buchert, M.; Steenari, B.-M.; Van Gerven, T.; Jones, P. T. J. J. o. S. M., REE recovery from end-of-life NdFeB permanent magnet scrap: a critical review. J. Sustain. Metall. 2017, 3 (1), 122-149.

21. Karraker, D., Coordination of trivalent lanthanide ions. Journal of Chemical Education 1970, 47 (6), 424.

22. Bünzli, J.-C. G., Lanthanide coordination chemistry: From old concepts to coordination polymers. Journal of Coordination Chemistry 2014, 1-45.

23. Helm, L.; Merbach, A. E., Inorganic and bioinorganic solvent exchange mechanisms. Chem Rev 2005, 105 (6), 1923-59.

24. Meier, D. J.; Garner, C. S., The Kinetics of the Europium (II)-Europium (III) Exchange Reaction. The Journal of Physical Chemistry 1952, 56 (7), 853-857. 25. Sørensen, T. J.; Faulkner, S., Multimetallic Lanthanide Complexes: Using Kinetic Control To Define Complex Multimetallic Arrays. Acc Chem Res 2018, 51 (10), 2493-2501.

26. Nielsen, L. G.; Sørensen, T. J., Including and Declaring Structural Fluctuations in the Study of Lanthanide(III) Coordination Chemistry in Solution. Inorganic Chemistry 2019, 59 (1), 94-105.

27. Nawrocki, P. R.; Kofod, N.; Juelsholt, M.; Jensen, K. M. Ø.; Sørensen, T. J., The effect of weighted 
averages when determining the speciation and structureproperty relationships of europium(iii) dipicolinate complexes. Physical Chemistry Chemical Physics 2020, 22 (22), 12794-12805.

28. Garda, Z.; Nagy, V.; Rodríguez-Rodríguez, A.; Pujales-Paradela, R.; Patinec, V.; Angelovski, G.; Tóth, É.; Kálmán, F. K.; Esteban-Gómez, D.; Tripier, R.; PlatasIglesias, C.; Tircsó, G., Unexpected Trends in the Stability and Dissociation Kinetics of Lanthanide(III) Complexes with Cyclen-Based Ligands across the Lanthanide Series. Inorganic chemistry 2020, 59 (12), 8184-8195.

29. Cotton, S., Lanthanide and Actinide Chemistry. Wiley: Chichester, 2006.

30. Bordes, A.; Poveda, A.; Troadec, T.; Franconetti, A.; Arda, A.; Perrin, F.; Menand, M.; Sollogoub, M.; Guillard, J.; Desire, J.; Tripier, R.; Jimenez-Barbero, J.; Bleriot, Y., Synthesis, Conformational Analysis, and Complexation Study of an Iminosugar-Aza-Crown, a Sweet Chiral Cyclam Analog. Organic letters 2020.

31. Franklin, S. J.; Raymond, K. N., Solution Structure and Dynamics of Lanthanide Complexes of the Macrocyclic Polyamino Carboxylate DTPA-dien. NMR Study and Crystal Structures of the Lanthanum(II1) and Europium(II1) Complexes. Inorganic chemistry 1994, 33, 5794-5804. 32. Webber, B. C.; Payne, K. M.; Rust, L. N.; Cassino, C.; Carniato, F.; McCormick, T.; Botta, M.; Woods, M., Analysis of the Relaxometric Properties of Extremely Rapidly Exchanging Gd3+ Chelates: Lessons from a Comparison of Four Isomeric Chelates. Inorganic chemistry 2020, 59 (13), 9037-9046.

33. Persson, I.; D'Angelo, P.; De Panfilis, S.; Sandström, M.; Eriksson, L., Hydration of Lanthanoid(III) Ions in Aqueous Solution and Crystalline Hydrates Studied by EXAFS Spectroscopy and Crystallography: The Myth of the "Gadolinium Break". Chemistry - A European Journal 2008, 14 (10), 3056-3066.

34. Peters, J. A.; Djanashvili, K.; Geraldes, C. F. G. C.; Platas-Iglesias, C., The chemical consequences of the gradual decrease of the ionic radius along the Ln-series. Coordination Chemistry Reviews 2020, 406, 213146.

35. Shannon, R. D., Revised effective ionic radii and systematic studies of interatomic distances in halides and chalcogenides. Acta crystallographica section A 1976, 32 (5), 751-767.

36. Housecroft, C. E.; Sharpe, A. G., Inorganic Chemistry 4th ed. Pearson: 2012.

37. Seitz, M.; Oliver, A. G.; Raymond, K. N. J. J. o. t. A. C. S., The lanthanide contraction revisited. J. Am. Chem. Soc. 2007, 129 (36), 11153-11160.

38. Spedding, F.; Jones, K., Heat capacities of aqueous rare earth chloride solutions at 25 . The Journal of Physical Chemistry

1966, 70 (8), 2450-2455.

39. Spedding, F.; Pikal, M., Relative viscosities of some aqueous rare earth chloride solutions at $25^{\circ}$. The Journal of Physical Chemistry 1966, 70 (8), 2430-2440. 40. Spedding, F. H.; Pikal, M.; Ayers, B., Apparent molal volumes of some aqueous rare earth chloride and nitrate solutions at 25. The Journal of Physical Chemistry 1966, 70 (8), 2440-2449.

41. Cossy, C.; Helm, L.; Powell, D. H.; Merbach, A. E., A change in coordination number from nine to eight along the lanthanide (III) aqua ion series in solution: a neutron diffraction study. New Journal of Chemistry 1995.
42. Yamaguchi, T.; Nomura, M.; Wakita, H.; Ohtaki, $H$., An extended $x$-ray absorption fine structure study of aqueous rare earth perchlorate solutions in liquid and glassy states. The Journal of chemical physics 1988, 89 (8) 5153-5159.

43. Cossy, C.; Helm, L.; Merbach, A. E., Oxygen-17 nuclear magnetic resonance kinetic study of water exchange on the lanthanide(III) aqua ions. Inorganic Chemistry 1988, 27 (11), 1973-1979.

44. Spezia, R.; Duvail, M.; Vitorge, P.; D'Angelo, P. In Molecular dynamics to rationalize EXAFS experiments: $A$ dynamical model explaining hydration behaviour across the lanthanoid (III) series, Journal of Physics: Conference Series, IOP Publishing: 2009; p 012056.

45. Rudolph, W.; Irmer, G., On the hydration of heavy rare earth ions: $\mathrm{Ho} 3+, \mathrm{Er} 3+, \mathrm{Tm} 3+, \mathrm{Yb} 3+$ and $\mathrm{Lu} 3+-\mathrm{a}$ Raman study. Molecules 2019, 24 (10), 1953.

46. Rudolph, W. W.; Irmer, G., On the Hydration of the Rare Earth lons in Aqueous Solution. Journal of Solution Chemistry 2020, 1-16.

47. Janicki, R.; Mondry, A., Structural and thermodynamic aspects of hydration of Gd (III) systems. Dalton Transactions 2019, 48 (10), 3380-3391.

48. Morales, N.; Galbis, E.; Martinez, J. M.; Pappalardo, R. R.; Sanchez Marcos, E., Identifying Coordination Geometries of Metal Aquaions in Water: Application to the Case of Lanthanoid and Actinoid Hydrates. The journal of physical chemistry letters 2016, 7 (21), 4275-4280.

49. Zhang, J.; Heinz, N.; Dolg, M., Understanding lanthanoid (III) hydration structure and kinetics by insights from energies and wave functions. Inorganic Chemistry 2014, 53 (14), 7700-7708.

50. Thomson, J. J., XXIV. On the structure of the atom: an investigation of the stability and periods of oscillation of a number of corpuscles arranged at equal intervals around the circumference of a circle; with application of the results to the theory of atomic structure. The London, Edinburgh, and Dublin Philosophical Magazine and Journal of Science 1904, 7 (39), 237-265.

51. Cotton, S.; Harrowfield, J., Solvento complexes of the lanthanide ions. The Rare Earth Elements 2012, 55-63. 52. Drew, M. G., Structures of high coordination complexes. Coordination Chemistry Reviews 1977, 24 (23), 179-275.

53. Drew, M. G., Seven-coordination chemistry. Progress in Inorganic Chemistry 1977, 23.

54. Hyde, K. E., Methods for obtaining RussellSaunders term symbols from electronic configurations. Journal of Chemical Education 1975, 52 (2), 87.

55. Rinehart, J. D.; Long, J. R., Exploiting single-ion anisotropy in the design of f-element single-molecule magnets. Chemical Science 2011, 2 (11), 2078-2085. 56. Bünzli, J.-C. G.; Eliseeva, S. V., Lanthanide Luminescence. 2011.

57. Tanner, P. A., Some misconceptions concerning the electronic spectra of tri-positive europium and cerium. Chemical Society Reviews 2013, 42 (12), 5090-5101. 58. Alvarez, S.; Alemany, P.; Casanova, D.; Cirera, J.; Llunell, M.; Avnir, D., Shape maps and polyhedral interconversion paths in transition metal chemistry. Coordination chemistry reviews 2005, 249 (17-18), 16931708. 
59. Casanova, D.; Llunell, M.; Alemany, P.; Alvarez, $\mathrm{S}$., The rich stereochemistry of eight-vertex polyhedra: a continuous shape measures study. Chemistry-A European Journal 2005, 11 (5), 1479-1494.

60. Ruiz-Martínez, A.; Alvarez, S., Stereochemistry of compounds with coordination number ten. Chemistry $-A$ European Journal 2009, 15 (30), 7470-7480.

61. Kofod, N.; Arppe-Tabbara, R.; Sørensen, T. J., Electronic Energy Levels of Dysprosium(III) ions in Solution. Assigning the Emitting State and the Intraconfigurational 4 f$4 \mathrm{f}$ Transitions in the Vis-NIR Region and Photophysical Characterization of Dy(III) in Water, Methanol, and Dimethyl Sulfoxide. The Journal of Physical Chemistry A 2019, 123 (13), 2734-2744

62. Kofod, N.; Nawrocki, P.; Juelsholt, M.; Christiansen, T. L.; Jensen, K. M. Ø.; Sørensen, T. J., Solution Structure, Electronic Energy Levels, and Photophysical Properties of $[\mathrm{Eu}(\mathrm{MeOH}) \mathrm{n}-2 \mathrm{~m}(\mathrm{NO} 3) \mathrm{m}] 3-\mathrm{m}+$ Complexes. Inorganic Chemistry 2020.

63. Esteban-Gómez, D.; Büldt, L. A.; Pérez-Lourido, P.; Valencia, L.; Seitz, M.; Platas-Iglesias, C., Understanding the Optical and Magnetic Properties of Ytterbium(III) Complexes. Inorganic Chemistry 2019, 58 (6), 3732-3743.

64. Chilton, N. F.; Goodwin, C. A.; Mills, D. P.; Winpenny, R. E., The first near-linear bis (amide) f-block complex: a blueprint for a high temperature single molecule magnet. Chemical Communications 2015, 51 (1), 101-103. 65. Ungur, L.; Le Roy, J. J.; Korobkov, I.; Murugesu, M.; Chibotaru, L. F., Fine-tuning the Local Symmetry to Attain Record Blocking Temperature and Magnetic Remanence in a Single-Ion Magnet. Angewandte Chemie 2014, 126 (17), 4502-4506.

66. Vonci, M.; Mason, K.; Suturina, E. A.; Frawley, A T.; Worswick, S. G.; Kuprov, I.; Parker, D.; McInnes, E. J. L.; Chilton, N. F., Rationalization of Anomalous

Pseudocontact Shifts and Their Solvent Dependence in a Series of C3-Symmetric Lanthanide Complexes. Journal of the American Chemical Society 2017, 139 (40), 1416614172.

67. Mason, K.; Harnden, A. C.; Patrick, C. W.; Poh, A. W. J.; Batsanov, A. S.; Suturina, E. A.; Vonci, M.; McInnes, E. J. L.; Chilton, N. F.; Parker, D., Exquisite sensitivity of the ligand field to solvation and donor polarisability in coordinatively saturated lanthanide complexes. Chemical Communications 2018, 54 (61), 84868489 .

68. Vonci, M.; Mason, K.; Neil, E. R.; Yufit, D. S.; Mclnnes, E. J. L.; Parker, D.; Chilton, N. F., Sensitivity of Magnetic Anisotropy in the Solid State for Lanthanide Complexes with Small Crystal Field Splitting. Inorganic Chemistry 2019, 58 (9), 5733-5745.

69. Tao, J.; Perdew, J. P.; Staroverov, V. N.; Scuseria, G. E., Climbing the density functional ladder: Nonempirical meta-generalized gradient approximation designed for molecules and solids. Physical Review Letters 2003, 91 (14), 146401.

70. Zhao, Y.; Truhlar, D. G., The M06 suite of density functionals for main group thermochemistry,

thermochemical kinetics, noncovalent interactions, excited states, and transition elements: two new functionals and systematic testing of four M06-class functionals and 12 other functionals. Theoretical Chemistry Accounts 2008 , $120(1-3), 215-241$.
71. Roca-Sabio, A.; Regueiro-Figueroa, M.; EstebanGómez, D.; de Blas, A.; Rodríguez-Blas, T.; PlatasIglesias, C., Density functional dependence of molecular geometries in lanthanide (III) complexes relevant to bioanalytical and biomedical applications. Computational Theoretical Chemistry 2012, 999, 93-104.

72. Djanashvili, K.; Platas-Iglesias, C.; Peters, J. A., The structure of the lanthanide aquo ions in solution as studied by 170 NMR spectroscopy and DFT calculations. Dalton Transactions 2008, (5), 602-607.

73. Zhang, J.; Meng, S.; Song, Y.; Yang, J.; Wei, H.; Huang, W.; Cifuentes, M. P.; Humphrey, M. G.; Zhang, C., Syntheses and NLO properties of 1D heterothiometallic anionic W/S/Ag clusters possessing solvento-ytterbium cation-directed isomeric skeletons. New Journal of Chemistry 2011, 35 (2), 328-338.

74. Dolg, M.; Stoll, H.; Savin, A.; Preuss, H., Energyadjusted pseudopotentials for the rare earth elements. Theoretica chimica acta 1989, 75 (3), 173-194.

75. Tomasi, J.; Mennucci, B.; Cammi, R., Quantum mechanical continuum solvation models. Chem Rev 2005, 105 (8), 2999-3094.

76. Frisch, M.; Trucks, G.; Schlegel, H. B.; Scuseria, G. E.; Robb, M. A.; Cheeseman, J. R.; Scalmani, G.; Barone, V.; Mennucci, B.; Petersson, G., gaussian 09, Revision d. 01, Gaussian. Inc., Wallingford CT 2009, 201. 77. Malmqvist, P.-Å.; Roos, B. O., The CASSCF state interaction method. Chemical physics letters 1989, 155 (2), 189-194.

78. Neese, F., The ORCA program system. Wiley Interdisciplinary Reviews: Computational Molecular Science 2012, 2 (1), 73-78.

79. Neese, F., Software update: the ORCA program system, version 4.0. Wiley Interdisciplinary Reviews: Computational Molecular Science 2018, 8 (1), e1327. 80. Slater, J. C.; Phillips, J. C., Quantum theory of molecules and solids Vol. 4: the self-consistent field for molecules and solids. PhT 1974, 27 (12), 49.

81. Vosko, S. H.; Wilk, L.; Nusair, M., Accurate spindependent electron liquid correlation energies for local spin density calculations: a critical analysis. Canadian Journal of physics 1980, 58 (8), 1200-1211.

82. Barysz, M.; Sadlej, A. J., Two-component methods of relativistic quantum chemistry: from the Douglas-Kroll approximation to the exact two-component formalism. Journal of Molecular Structure: THEOCHEM 2001, 573 (13), 181-200.

83. Reiher, M., Douglas-Kroll-Hess Theory: a relativistic electrons-only theory for chemistry. Theoretical Chemistry Accounts 2006, 116 (1-3), 241-252.

84. Aravena, D.; Neese, F.; Pantazis, D. A., Improved segmented all-electron relativistically contracted basis sets for the lanthanides. Journal of Chemical Theory Computation 2016, 12 (3), 1148-1156.

85. Weigend, F.; Ahlrichs, R., Balanced basis sets of split valence, triple zeta valence and quadruple zeta valence quality for $\mathrm{H}$ to $\mathrm{Rn}$ : Design and assessment of accuracy. Physical Chemistry Chemical Physics 2005, 7 (18), 3297-3305.

86. $\quad$ Pantazis, D. A.; Chen, X.-Y.; Landis, C. R.; Neese, F., All-electron scalar relativistic basis sets for thirdrow transition metal atoms. Journal of chemical theory computation 2008, 4 (6), 908-919. 
87. Kollmar, C.; Sivalingam, K.; Helmich-Paris, B Angeli, C.; Neese, F., A perturbation-based super-Cl approach for the orbital optimization of a CASSCF wave function. Journal of computational chemistry 2019, 40 (14), 1463-1470.

88. Stoychev, G. L.; Auer, A. A.; Neese, F., Automatic generation of auxiliary basis sets. Journal of chemical theory computation 2017, 13 (2), 554-562.

89. Kossmann, S.; Neese, F., Comparison of two efficient approximate Hartee-Fock approaches. Chemical Physics Letters 2009, 481 (4-6), 240-243.

90. Angeli, C.; Cimiraglia, R.; Evangelisti, S.; Leininger, T.; Malrieu, J.-P., Introduction of n-electron valence states for multireference perturbation theory. The Journal of Chemical Physics 2001, 114 (23), 10252-10264.

91. Angeli, C.; Cimiraglia, R.; Malrieu, J.-P., Nelectron valence state perturbation theory: a fast implementation of the strongly contracted variant. Chemical physics letters 2001, 350 (3-4), 297-305.

92. Angeli, C.; Cimiraglia, R.; Malrieu, J.-P., n-electron valence state perturbation theory: A spinless formulation and an efficient implementation of the strongly contracted and of the partially contracted variants. The Journal of chemical physics 2002, 117 (20), 9138-9153.

93. Marenich, A. V.; Cramer, C. J.; Truhlar, D. G., Universal solvation model based on solute electron density and on a continuum model of the solvent defined by the bulk dielectric constant and atomic surface tensions. The Journal of Physical Chemistry B 2009, 113 (18), 6378-6396. 94. Neese, F., Efficient and accurate approximations to the molecular spin-orbit coupling operator and their use in molecular g-tensor calculations. The Journal of chemical physics 2005, 122 (3), 034107.

95. Horrocks Jr, W. D.; Sudnick, D. R., Lanthanide ion probes of structure in biology. Laser-induced luminescence decay constants provide a direct measure of the number of metal-coordinated water molecules. Journal of the American Chemical Society 1979, 101 (2), 334-340.

96. Clarkson, I.; Dickins, R. S.; de Sousa, A. S., Nonradiative deactivation of the excited states of europium, terbium and ytterbium complexes by proximate energymatched $\mathrm{OH}, \mathrm{NH}$ and $\mathrm{CH}$ oscillators: an improved luminescence method for establishing solution hydration states. Journal of the Chemical Society, Perkin

Transactions 2 1999, (3), 493-504.

97. Flanagan, B. M.; Bernhardt, P. V.; Krausz, E. R.; Lüthi, S. R.; Riley, M. J., A Ligand-Field Analysis of the trensal (H3trensal= 2, 2', 2 " - Tris (salicylideneimino) triethylamine) Ligand. An Application of the Angular Overlap Model to Lanthanides. Inorganic chemistry 2002, 41 (20), 5024-5033.

98. Duan, C.-K.; Tanner, P. A., What Use Are Crystal Field Parameters? A Chemist's Viewpoint. The Journal of Physical Chemistry A 2010, 114 (19), 6055-6062.

99. Blackburn, O. A.; Tropiano, M.; Sørensen, T. J.; Thom, J.; Beeby, A.; Bushby, L. M.; Parker, D.; Natrajan, L. S.; Faulkner, S., Luminescence and upconversion from thulium(III) species in solution. Physical chemistry chemical physics : PCCP 2012, 14 (38), 13378-84.

100. Nielsen, L. G.; Junker, A. K. R.; Sørensen, T. J., Composed in the f-block: solution structure and function of kinetically inert lanthanide(iii) complexes. Dalton

Transactions 2018, 47 (31), 10360-10376.
101. Clarkson, I.; Dickins, R.; de Sousa, A. J. J. o. t C. S., Perkin Transactions 2, Non-radiative deactivation of the excited states of europium, terbium and ytterbium complexes by proximate energy-matched $\mathrm{OH}, \mathrm{NH}$ and $\mathrm{CH}$ oscillators: an improved luminescence method for establishing solution hydration states. 1999, (3), 493-504 102. Allen, P.; Bucher, J.; Shuh, D.; Edelstein, N.; Craig, I., Coordination chemistry of trivalent lanthanide and actinide ions in dilute and concentrated chloride solutions. Inorganic Chemistry 2000, 39 (3), 595-601.

103. Cossy, C.; Barnes, A. C.; Enderby, J. E.; Merbach, A. E., The hydration of Dy3+ and $\mathrm{Yb} 3+$ in aqueous solution: A neutron scattering first order difference study. The Journal of chemical physics 1989, 90 (6), 32543260.

104. Mayanovic, R. A.; Jayanetti, S.; Anderson, A. J.; Bassett, W. A.; Chou, I.-M., The structure of Yb3+ aquo ion and chloro complexes in aqueous solutions at up to $500 \mathrm{C}$ and $270 \mathrm{MPa}$. The Journal of Physical Chemistry A 2002, 106 (28), 6591-6599.

105. Lim, K. C.; Skelton, B. W.; White, A. H., Structural Systematics of Rare Earth Complexes. XXII.('Maximally') Hydrated Rare Earth lodides. Australian Journal of Chemistry 2000, 53 (10), 867-873.

106. Chatterjee, A.; Maslen, E. N.; Watson, K. J., The effect of the lanthanoid contraction on the nonaaqualanthanoid(III) tris(trifluoromethanesulfonates). Acta Crystallographica Section B 1988, 44 (4), 381-386. 107. Kuta, J.; Clark, A. E., Trends in Aqueous Hydration Across the $4 \mathrm{f}$ Period Assessed by Reliable Computational Methods. Inorganic Chemistry 2010, 49 (17), 7808-7817. 108. Esteban-Gómez, D.; de Blas, A.; Rodríguez-Blas, T.; Helm, L.; Platas-Iglesias, C., Hyperfine Coupling Constants on Inner-Sphere Water Molecules of GdIII-Based MRI Contrast Agents. ChemPhysChem 2012, 13 (16), 3640-3650.

109. Regueiro-Figueroa, M.; Platas-Iglesias, C., Toward the Prediction of Water Exchange Rates in Magnetic Resonance Imaging Contrast Agents: A Density Functional Theory Study. The Journal of Physical Chemistry A 2015, 119 (24), 6436-6445.

110. Baranyai, Z.; Delli Castelli, D.; Platas-Iglesias, C.; Esteban-Gomez, D.; Bényei, A.; Tei, L.; Botta, M., Combined NMR, DFT and X-ray studies highlight structural and hydration changes of [Ln(AAZTA)]- complexes across the series. Inorganic Chemistry Frontiers 2020, 7 (3), 795803.

111. Rudolph, W. W.; Pye, C. C., Raman spectroscopic measurements of scandium (III) hydration in aqueous perchlorate solution and ab initio molecular orbital studies of scandium (III) water clusters: does Sc (III) occur as a hexaaqua complex? The Journal of Physical Chemistry $A$ 2000, 104 (8), 1627-1639.

112. Esteban-Gómez, D.; Cassino, C.; Botta, M.; Platas-Iglesias, C., $17 \mathrm{O}$ and $1 \mathrm{H}$ relaxometric and DFT study of hyperfine coupling constants in [Mn (H 2 O) 6] 2+. RSC Advances 2014, 4 (14), 7094-7103.

113. Shiery, R. C.; Fulton, J. L.; Balasubramanian, M.; Nguyen, M.-T.; Lu, J.-B.; Li, J.; Rousseau, R.; Glezakou, V.-A.; Cantu, D. C., Coordination Sphere of Lanthanide Aqua Ions Resolved with Ab Initio Molecular Dynamics and X-ray Absorption Spectroscopy. Inorganic Chemistry 2021. 